\title{
Diagnosis and management of a patient with idiopathic macular telangiectasia type 2
}

\author{
Ioannis Mallias, Panagiota Mylova, Anastasia Tassiopoulou \\ Laser Plus Eye, Nea Smyrni, Athens, Greece
}

\begin{abstract}
This is a case report discussing the case of a patient with idiopathic macular telangiectasia type 2 . The diagnosis and the management of the patient are analysed as well as the possible factors that attribute to the appearance of idiopathic macular telangiectasia.
\end{abstract}

KEY WORDS: MacTel, MacTel 2, macular telangiectasia type 2

Ophthalmol J 2017; Vol. 2, No. 3, 83-86

\section{INTRODUCTION}

Macular telangiectasia (MacTel) is a condition of the retina, which leads to abnormalities of capillaries of the fovea or the perifoveal region [1,2]. It is associated with loss of the outer nuclear layers and ellipsoid zone that can progress to cystic cavitation-like changes in all retinal layers, development of full-thickness macular holes, or subretinal neovascularisation in advanced stages.

Macular telangiectasia is divided into three categories [2]:

- MacTel type 1, which is a congenital form of the disease and is unilateral. MacTel type 1 is an uncommon form of the disease;

- MacTel type 2, which is the most common form of the three types. It is acquired and bilateral and is more common in middle-aged or older patients. There are studies indicating that MacTel type 2 is more common in female patients;

- MacTel type 3 exists but is extremely rare. Patients with Type 3 tend to have more vessels diseased, causing the blood vessels to become occluded.

Macular telangiectasia type 1 [2] is probably best defined as an acquired capillary ectasia and dilation in the parafoveal region, leading to vascular incompetence. The telangiectatic vessels develop micro-aneurysms, which subsequently leak fluid, blood, and occasionally lipid. Macular telangiectasia type 1 has been described as a variant of Coats' disease, which is defined by extensive peripheral retinal telangiectasis, exudative retinal detachment, relatively young age of onset, and male predilection. The precise aetiology is unknown but it has been speculated that chronic venous congestion caused by obstruction of the retinal veins as they cross retinal arteries at the horizontal raphe may be a contributory factor.

In macular telangiectasia type 2 histopathology studies [3, 4] have shown a loss of Mueller cell markers in the clinically altered area, suggesting that Mueller cell death may be involved in the pathogenesis. Due to the relatively recent manifestation of MacTel (last 25 years) there is not much information about the aetiology and the course of the disease. Hence there is a big study underway, called the MacTel Project, which is an international research collaboration among clinicians and bench scientists to study idiopathic macular telangiectasia type 2, which the most common of the three forms, as mentioned above.

The MacTel project has found a prevalence of diabetes mellitus (28\%) and hypertension (52\%) in MacTel type 2 [2-4]. These facts, combined with the age that the disease appears (60 years old or 


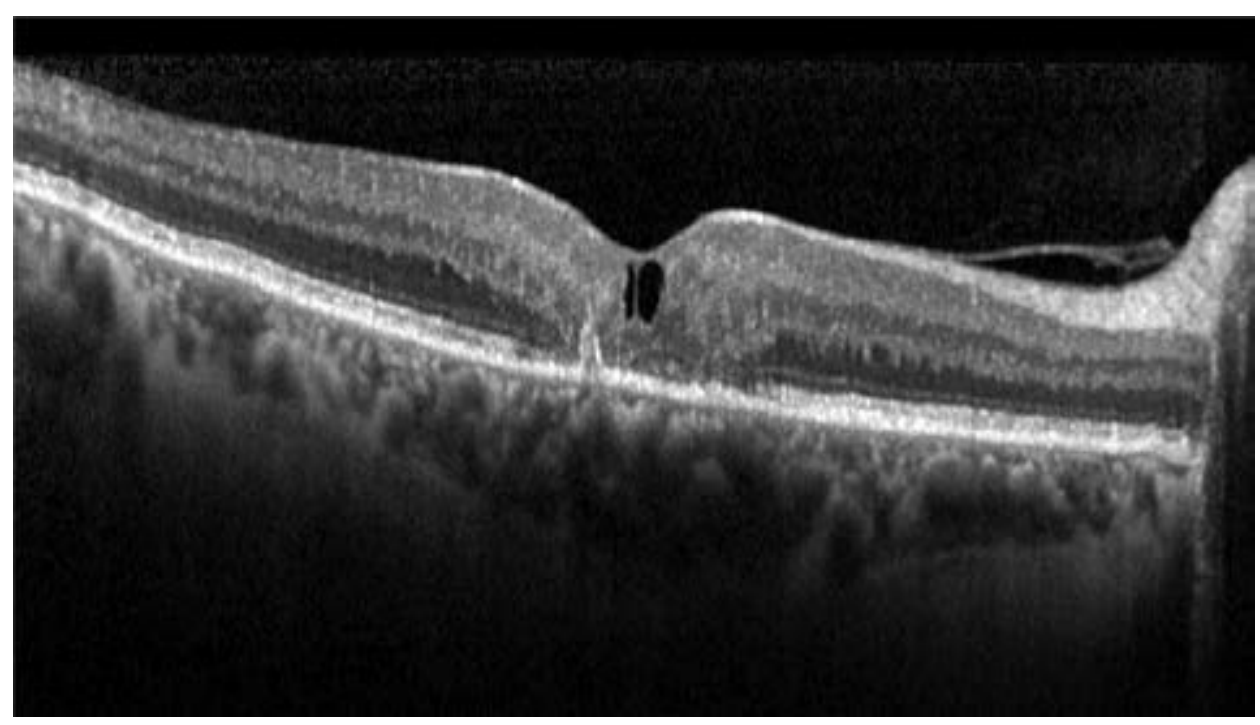

FIGURE 1. OCT examination of the right eye

above), point toward long-term vascular stress as the aetiology of this disease.

The diagnosis of MacTel is made by ophthalmological clinical examination and fundus imaging. Patient history and symptoms $[3,4]$ might be helpful for the diagnosis. Patients with MacTel type 2 complain about metamorphopsia or scotoma. As the disease progresses, an increased scotoma can be perceived with decreased visual acuity as the condition affects the fovea and perifoveal area. Visual acuity in MacTel type 2 usually stays at 20/32 or better according to the Mac Tel Project, and it can decrease if a macular hole develops. Vision can be severely diminished in MacTel type 1 and 3.

Fundoscopically, in MacTel type 2, foveal or perifoveal ectatic vessels with possible presence of venules diving at a right angle into deeper retinal layers are observed $[2,3]$. Greyish discoloration of the temporal perifoveal area is the earliest sign. Subretinal neovascularisation temporal to the fovea may be seen in this disease, and it can be associated with exudates or haemorrhage. RPE (Retinal Pigment Epithelium) hyperplasia can also be seen at the fovea or temporal perifovea. Also, in later stages, pseudolamellar holes can develop into full-thickness macular holes.

In optical coherence tomography (OCT) [5, 6], temporal foveal pit enlargement due to loss of outer nuclear layer and ellipsoid zone that can progress into large cysts, which can encompass all retinal layers. Hyper-reflective areas $[7,8]$ on OCT correlate to areas of RPE hyperplasia and migration. In a fluorescein angiography of a patient with MacTel type 2, temporal foveal telangiectatic vessels appear, which leak in later stages. Evidence of venules div- ing at a right angle into deeper retinal layers can also be seen. Subretinal neovascularisation has been shown to be retinal in origin because fluorescein angiography shows a feeding arteriole and a draining venule.

Because of the lack of knowledge we have about this disease, there is still much to be understood about it. Some patients may only need careful monitoring and may not need treatment at all. If the blood vessels begin to leak fluid and cause swelling and scarring, laser treatments will help relieve the swelling and reduce complication. Steroids are sometimes used to minimise $[9,10]$ inflammation, and drugs such anti-VEGF [9-12] (vascular endothelial growth factor) are being used to stop abnormal blood vessel growth.

\section{CASE REPORT}

A 68-year-old female visited the office for examination, complaining about gradual vision loss over the last decade in both eyes. Over the last months she has noticed a rapid deterioration of the vision of her right eye as well. Her best corrected visual acuity (BCVA) was 20/200 on the right eye and 20/30 on her left eye. The patient was dilated and Dr Mallias performed a thorough fundus examination. The patient was also examined with optical coherence tomography (OCT), and the findings were the following.

On the right eye, degenerations were observed on the fovea and on ISOS (photoreceptors and pigment epithelium complex) along with a cystic space on the inner layers of the retina, at the area of the fovea (Fig. 1). 


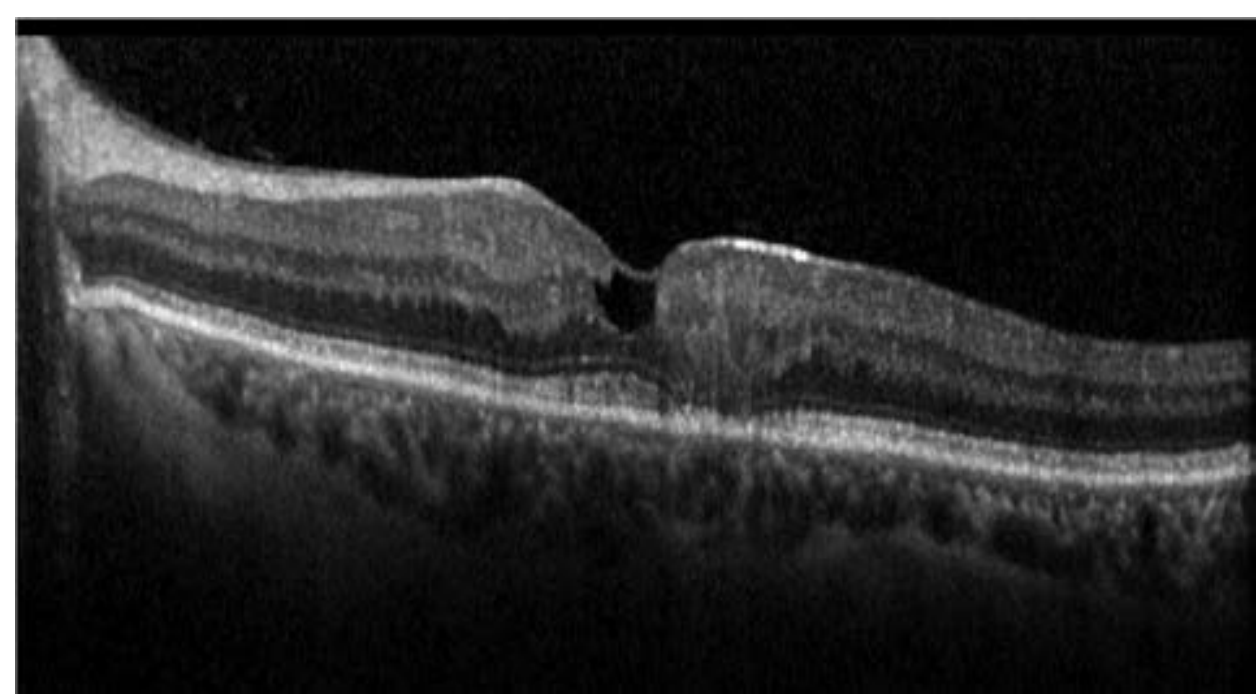

FIGURE 2. OCT examination of the left eye
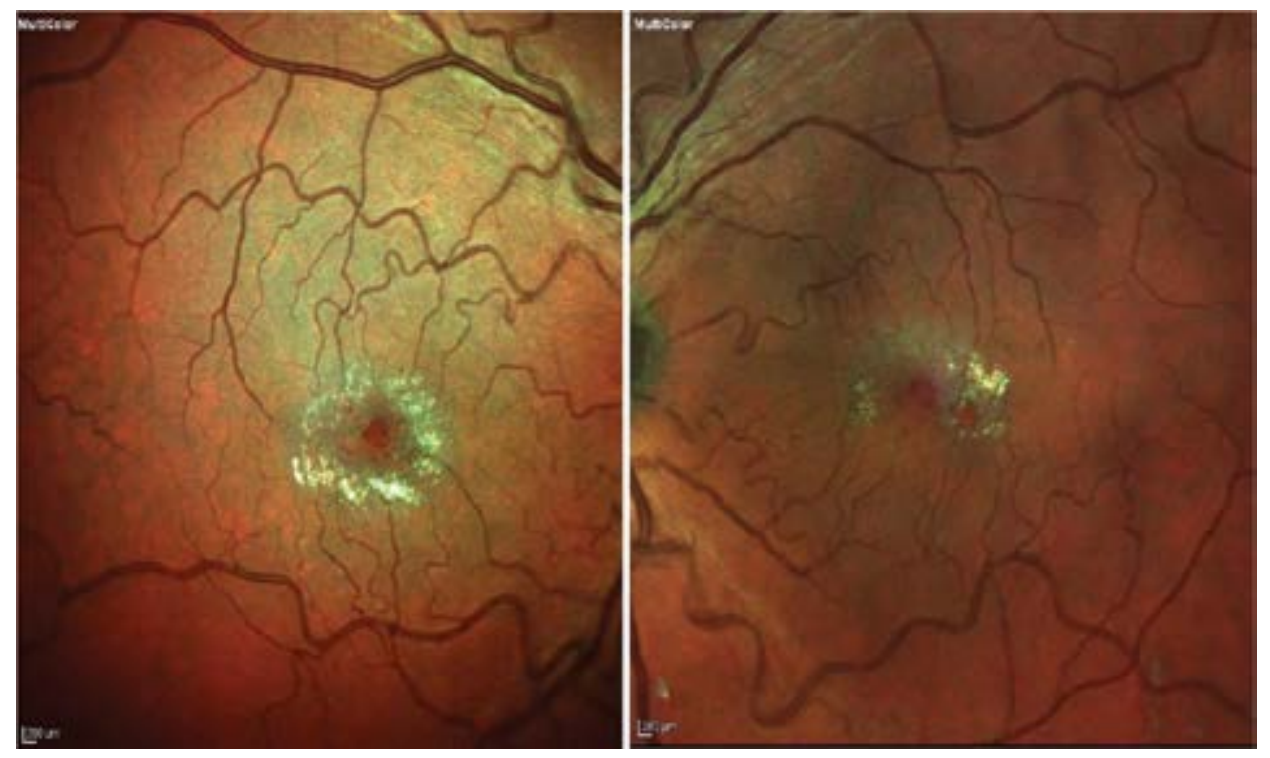

FIGURE 3. Multicolour examination of both eyes

On the left eye, degenerations were observed on ISOS parafoveally, along with a cystic space on the inner layers of the retina, at the area of the fovea (Fig. 2).

On the multicolour examination (Fig. 3), whitish hyper reflective areas were observed parafoveally on both eyes. The above findings are consistent with macular telangiectasia type 2 (MacTel type 2).

\section{DISCUSSION}

As already mentioned, MacTel type 2 may be the most common of the three types of the disease, but the disease is very rare in general. Usually, there is not such a dramatic loss of vision, especially in cases where a macular hole has not yet occurred. However, in this case, the BCVA on the right eye was 20/200 without the existence of a full thickness macular hole. That loss of visual acuity on the right eye can be explained by the loss of photoreceptors on the fovea. What should be noted is that the patient did not have a history of diabetes mellitus or hypertension in order to (partially) justify the appearance of MacTel type 2. This fact leads to the assumption that in this case the background of the disease was genetic. 
MacTel should be differentially diagnosed from diabetic retinopathy or radiation retinopathy. In cases of neovascularisation, one should be careful to distinguish MacTel from age-related macular degeneration. The pseudolamellar holes in the early stages that can develop into full-thickness macular holes due to MacTel should be differentially diagnosed from idiopathic macular holes and lamellar macular holes. If these macular holes exist due to $\mathrm{MacTel}$ then they should not be operated on because the outcome will not be optimal.

Photocoagulation was recommended, and remains to date the main treatment. It seems to be successful in causing resolution of exudation and visual acuity improvement or stabilisation in some patients [13, 14]. Photocoagulation should be used in order to reduce the chance of producing a symptomatic paracentral scotoma and metamorphopsia. Small burns $(100-200 \mu \mathrm{m})$ of moderate intensity in a grid-pattern and on multiple occasions, if necessary, are recommended. It is unnecessary to destroy every dilated capillary, and, particularly during the initial session of photocoagulation, those on the edge of the capillary-free zone should be avoided [14].

In one reported patient with macular telangiectasia type I, a single intravitreal bevacizumab injection resulted in a marked increase in visual acuity from $20 / 50$ to $20 / 20$, with significant and sustained decrease in both leakage on fluorescein angiography and cystoid macular oedema on OCT up to 12 months [15]. It is likely that patients with macular telangiectasia type I with pronounced macular oedema from leaky telangiectasis may benefit functionally and morphologically from intravitreal anti-VEGF injections, but this needs to be further investigated.

The use of vascular endothelial growth factor (VEGF) inhibitors, which have proven successful in treating age-related macular degeneration, have not proven to be effective in non-proliferative MacTel type 2 [16]. Anti-VEGF reduces the vascular leak seen on angiography, although microperimetry suggests that neural atrophy may still proceed in treated eyes. In proliferative stages (neovascularisation), treatment with Anti-VEGF can be helpful.

Triamcinolone acetonide has proven to be beneficial in the treatment of macular oedema by their anti-inflammatory effect, their downregulation of VEGF production, and stabilisation of the blood retinal barrier $[17,18]$. However, it is not used frequently due to the side effects (elevated intraocular pressure, cataract).

\section{REFERENCES}

1. Wu L, Evans T, Arevalo JF. Idiopathic macular telangiectasia type 2 (idiopathic juxtafoveolar retinal telangiectasis type 2A, Mac Tel 2). Surv Ophthalmol. 2013; 58(6): 536-559, doi: 10.1016/j.survophthal.2012.11.007, indexed in Pubmed: 24160729.

2. Clemons TE, Gillies MC, Chew EY, et al. Macular Telangiectasia Project Research Group. Medical characteristics of patients with macular telangiectasia type 2 (MacTel Type 2) MacTel project report no. 3. Ophthalmic Epidemiol. 2013; 20(2): 109-113, doi: 10.3109/09286586.2013.766757, indexed in Pubmed: 23510315.

3. Sallo FB, Leung I, Zeimer M, et al. MacTel Study Group. Abnormal retinal reflectivity to short-wavelength light in type 2 idiopathic macular telangiectasia. Retina. 2017 [Epub ahead of print], doi: 10.1097/ IAE.0000000000001728, indexed in Pubmed: 28644304.

4. Heeren TFC, Clemons T, Scholl HPN, et al. Progression of vision loss in macular telangiectasia type 2. Invest Ophthalmol Vis Sci. 2015; 56(6): 3905-3912, doi: 10.1167/iovs. 15-16915, indexed in Pubmed: 26070062.

5. Sallo FB, Leung I, Clemons TE, et al. MacTel CNTF Research Group. Correlation of structural and functional outcome measures in a phase one trial of ciliary neurotrophic factor in type 2 idiopathic macular telangiectasia. Retina. 2017 [Epub ahead of print], doi: 10.1097/ IAE.0000000000001706, indexed in Pubmed: 28541963.

6. Gonzalez MA, Shechtman D, Haynie JM, et al. Unveiling idiopathic macular telangiectasia: clinical applications of optical coherence tomography angiography. Eur J Ophthalmol. 2017; 27(4): e129-e133, doi: 10.5301/ejo.5000984, indexed in Pubmed: 28525681.

7. Chidambara L, Gadde SGK, Yadav NK, et al. Characteristics and quantification of vascular changes in macular telangiectasia type 2 on optical coherence tomography angiography. Br J Ophthalmol. 2016; 100(11): 1482-1488, doi: 10.1136/bjophthalmol-2015-307941, indexed in Pubmed: 26823394.

8. Toto L, Di Antonio L, Mastropasqua R, et al. Multimodal imaging of macular telangiectasia type 2: Focus on vascular changes using optical coherence tomography angiography. Invest Ophthalmol Vis Sci. 2016; 57(9): OCT268-OCT276, doi: 10.1167/iovs.15-18872, indexed in Pubmed: 27409482.

9. Alkin Z, Yilmaz I, Ozkaya A, et al. Anti-vascular endothelial growth factor treatment for proliferative macular telangiectasia type 2. Middle East Afr J Ophthalmol. 2016; 23(2): 222-224, doi: 10.4103/09749233.171773, indexed in Pubmed: 27162458.

10. Chhablani J, Dedhia CJ, Peguda HK, et al. Short-term safety of $2 \mathrm{mg}$ intravitreal ziv-aflibercept. Retina. 2017; 37(10): 1859-1865, doi: 10.1097/IAE.0000000000001440, indexed in Pubmed: 28060148.

11. Aydoğan T, Erdoğan G, Ünlü C, et al. Intravitreal bevacizumab treatment in type 2 idiopathic macular telangiectasia. Turk J Ophthalmol. 2016; 46(6): 270-273, doi: 10.4274/tjo.23921, indexed in Pubmed: 28050323.

12. Toygar 0 , Guess MG, Youssef DS, et al. Long-term outcomes of intravitreal bevacizumab therapy for subretinal neovascularization secondary to idiopathic macular telangiectasia type 2. Retina. 2016; 36(11): 2150-2157, doi: 10.1097/IAE.0000000000001035, indexed in Pubmed: 27258671

13. Gass JD, Oyakawa RT. Idiopathic juxtafoveolar retinal telangiectasis. Arch Ophthalmol. 1982; 100(5): 769-780, indexed in Pubmed: 7082207.

14. Gass JD, Blodi BA. Idiopathic juxtafoveolar retinal telangiectasis. Update of classification and follow-up study. Ophthalmology. 1993; 100(10): 1536-1546, indexed in Pubmed: 8414413.

15. Gamulescu MA, Walter A, Sachs H, et al. Bevacizumab in the treatment of idiopathic macular telangiectasia. Graefes Arch Clin Exp Ophthalmol. 2008; 246(8): 1189-1193, doi: 10.1007/s00417-0080795-6, indexed in Pubmed: 18386039.

16. Charbel Issa P, Finger RP, Kruse K, et al. Monthly ranibizumab for nonproliferative macular telangiectasia type 2: a 12-month prospective study. Am J Ophthalmol. 2011; 151(5): 876-886.e1, doi: 10.1016/j. ajo.2010.11.019, indexed in Pubmed: 21334595.

17. Wilson C. Treatment with intravitreal steroid reduces blood-retinal barrier breakdown due to retinal photocoagulation. $\mathrm{Ar}$ chives of Ophthalmology. 1992; 110(8): 1155, doi: 10.1001/ archopht.1992.01080200135041.

18. Edelman JL, Lutz D, Castro MR. Corticosteroids inhibit VEGF-induced vascular leakage in a rabbit model of blood-retinal and blood-aqueous barrier breakdown. Exp Eye Res. 2005; 80(2): 249-258, doi: 10.1016/j. exer.2004.09.013, indexed in Pubmed: 15670803. 